\title{
An Ethical Practice Intervention Program for Pediatric Nurses with Varied Nursing Experience
}

\author{
Naomi Matsumori \\ Department of Nursing, Faculty of Health and Welfare, Prefectural University of Hiroshima, Hiroshima, Japan \\ Email: matumori@pu-hiroshima.ac.jp
}

How to cite this paper: Matsumori, N. (2020) An Ethical Practice Intervention Program for Pediatric Nurses with Varied Nursing Experience. Open Journal of Nursing, 10, 411-428.

https://doi.org/10.4236/ojn.2020.104028

Received: March 24, 2020

Accepted: April 24, 2020

Published: April 27, 2020

Copyright () 2020 by author(s) and Scientific Research Publishing Inc. This work is licensed under the Creative Commons Attribution International License (CC BY 4.0).

http://creativecommons.org/licenses/by/4.0/

\section{(c) (i) Open Access}

\begin{abstract}
Aim: This study aimed to elucidate experience-related differences in the impact of an intervention program promoting ethical nursing practices among pediatric nurses with $0-5$ years' experience in varying settings. Methods: The pediatric nursing care model, defining 24 elements of pediatric nursing practice, was developed to educate nurses with pediatric nursing experience only, as well as those with experience in other settings, on ethical nursing practices toward pediatric patients and their families. Participants' level of knowledge and frequency of application of these practices were assessed before, directly after and two months after the intervention, with a final follow-up three months post-intervention. Results: Results showed that among those who have experience in nursing areas other than pediatrics, the frequency of practicing items related to children's rights and dignity significantly increased $(\mathrm{p}<0.05)$. Among nurses who have experience only in pediatric nursing, improvement was observed in their practice, including details important in building a relationship of trust between patients and health professionals, information disclosure and supportive care $(\mathrm{p}<0.05)$. Conclusions: Participants showed an increased awareness of issues related to ethical pediatric nursing practice for patients' and their parents.
\end{abstract}

\section{Keywords}

Ethical Nursing Practice, Nursing Education, Pediatric Nursing, Pediatric Patient Care

\section{Introduction}

Pediatric patients require special treatment and nursing care, which differs from the care required by adult patients. There is currently no independent education 
system for pediatric nurses in Japan, and training follows a generalist approach. If a nurse is assigned to a pediatric department following graduation, they will receive specialist pediatric nursing training provided by the hospital where they are employed. Furthermore, there is currently no established continuous education system for Japanese nurses and, due to the country's increasingly aged population and decreasing birth rate, the proportion of general hospitals with pediatric departments relative to total hospitals has decreased from 45.7\% (4119 hospitals) in 1990 to $35.3 \%$ (2592) in 2017 [1]. An increasing number of pediatric wards have been merged with adult wards since 1994, with the proportion of mixed wards relative to total wards increasing from $54.5 \%$ in 1992 to $68.9 \%$ in 2013 [2] [3]. However, a number of issues have arisen in pediatric-adult mixed words, including nurse shortages, poor quality of pediatric care and education, and conflicts between pediatric and adult patients [4]. Kusayanagi (2004) found that nurses who work in mixed words felt they provided nurse-centered care to pediatric patients, while providing patient-centered care to adults; these nurses were exploring nursing specializations, while experiencing their practice in mixed wards as ambivalent, with no potential for refinement [5]. Kobayashi et al. (2008) reported that nurses working in a mixed ward demonstrated lower awareness of "children's best interests," compared to those working in a pediatric ward [6]. Ishiura et al. (2012) highlighted issues related to nursing ethics within a pediatric-adult mixed ward, stating that pediatric inpatients in such a ward tend to miss opportunities for play and developmental support due to the limiting social and physical environment of the ward [7]. Through the facilitation of regular study groups on pediatric nursing, these researchers proactively provided both nurses and children with an understanding of nursing practice that takes into account children's best interests. The necessity of an increase in awareness among nurses working in a mixed ward has been highlighted [8].

\section{Literature Review}

\subsection{Development of the Field in the UK as a Pioneer in Pediatric Nursing}

Since pediatric nursing involves interaction with patients' parents, pediatric nurses need to have a deep understanding of adults. Therefore, in 1955, the first course to combine a State Registered Nurses (SRNs) course and a Registered Sick Children's Nurses (RSCNs) course was introduced. In the past, nurses who wanted to specialize in pediatric nursing were advised to build experience through adult nursing early in their career. However, the Platt Report, issued in 1959 by the Committee on the Welfare of Children in Hospital, suggested that pediatric patients should be cared for by nurses who hold specialized qualifications [9]. The report also stated that pediatric nurses should continue their practice through focusing on the provision of care to children, and that those who specialized in adult nursing should provide care to pediatric patients only in exceptional cases. It was also suggested that cases where unqualified staff provided care to pediatric 
patients, advice from pediatric nurses should be sought; the implication of this recommendation was that specialized pediatric nurses should be on staff in any hospital where children received treatment.

Atherton (1993) referred to mixed-care wards as "grey areas" and recommended employing both adult and pediatric nurses [10]. According to Benner (1984), even a nurse with many years' experience is equivalent to an entry-level nurse when working in a clinical area he or she does not have experience in [11]. This highlights the inappropriateness of a single nursing qualification. We can no longer say it is appropriate for nurses to automatically obtain two qualifications. Moreover, a nurse's field of specialization is not determined prior to registration in a specialization. Aside from improving the quality of care, career satisfaction and background are important considerations for nurses.

Currently, motivated third-year registered nurses in the UK are allowed to take a 26-week course on pediatric nursing. The Audit Commission has pointed out that pediatric nursing is different from adult nursing and requires special skills and interaction with parents, raising the inadequacy of adult nursing qualifications for pediatric nurses [12].

In 2011, Southampton University launched a four-year bachelor program through which students could register for dual fields, namely adult and pediatric nursing [13]. This program broadly covers the two areas, allowing students to deepen their awareness of the importance and effects of family-centered care, and preparing them to work flexibly in various environments and with diverse teams in hospital and community settings. Students are also enabled to effectively and positively address the needs of pediatric patients transitioning to adulthood. The program emphasizes the need for newly employed registered nurses to receive training on the importance of protecting children and complying with their treatment plans. Some nurses have negative opinions on dual registration, and one-third of nurses work in a single area. It has been stated that the economic impact of the Southampton program on the National Health Service and the possibility of its expansion should be verified going forward.

\subsection{Development of the Field outside the UK}

Pediatric nursing had been a feature of the Irish healthcare system since 1821 . However, 2006 saw the institution of a 4.5 year-education program in which pediatric and general nursing were integrated, leading to a significant decrease in the number of pediatric nurses in this country. Specifically, and similar to the UK, the number of senior nurses who led the field decreased and, as a result, nurses who had never received special training for pediatric nursing have been engaged in pediatric care. As the number of complex and severe pediatric cases increase, requiring interaction with patients' families, as well as emergency and community care, specialist knowledge is increasingly required of nurses who provide pediatric care. Consequently, the demand for training of pediatric nurses, who can provide safe and practical care, has increased [14]. 
In Italy, general nursing (GN) and children's nursing $(\mathrm{CN})$ were recognized as independent professions for the first time in 1940. The managers of both general and pediatric hospitals prioritized the employment of GN nurses, who could be assigned to any ward. However, facilitating a deeper understanding of the role of pediatric nurses contributes to a reduction in healthcare cost, as it can contribute to avoiding negative outcomes and concomitant compensation for malpractice resulting from the utilization of untrained GNs in pediatrics, as well as additional training expenditure. In order to redefine the role of professional nurses in Italy in a logical and consistent way, Festini (2013) states that it is necessary to remove GNs who have not received postgraduate training from pediatric care, and recognize the skills of pediatric nurses [15].

Conway (1996) describes nurses' crises of confidence and difficulties transitioning from adult to pediatric nursing. She recounts the crisis she experienced when confronted with the pediatric "culture"; this is supported by Benner's theory [16].

Hollywood (2011) interviewed nurses who obtained qualifications for pediatric nursing following graduation, and phenomenologically analyzed their experience of career transition. The results indicated that what early career pediatric nurses need is support; mentorship and preceptor programs facilitate such support, and that the amount of support required is determined by past experience. According to this author, nurses who lack support plot their own career paths in the early stages of transition, based on their past experience [17].

Love (2005) describes specialized postgraduate education for pediatric oncology nursing and adult oncology nursing at McMaster University in the USA, linked with bachelor's education for generalist nurses. Nurses who have completed their generalist nursing education have raised concerns about their degree of specialization in cases where they work with cancer patients and their families, raising the necessity of the provision of specialist education through collaboration with universities. The USA faces an imminent nurse shortage, and it will soon be necessary for healthcare providers to employ more generalist nurses alongside those in other specialist areas, and this necessitates the identification, intervention and evaluation of issues related to cross-professional and cross-disciplinary collaboration and nursing career transition. In this regard, Runton and Toth (1998) developed a tool to assess basic knowledge of clinical pediatric nursing (PEDS-BKAT) to inform the reallocation of entry-level nurses and experienced nurses to pediatric ICUs [18] [19].

While several studies distinguish between pediatric and adult nursing, generalist nurses are required in certain cases, for example when healthcare system reform is implemented to address social and economic inequalities, or when there is a nurse shortage. The employment of generalist nurses in such situations allows flexibility. On the other hand, measures for improving the degree of specialization of pediatric nursing have been required and implemented, in order to appropriately treat severe and complex pediatric diseases and meet local demands for continuous nursing. 


\subsection{Context and Aims of the Present Study}

Taking into consideration the various debates about the field, there is a demand for enhancing ethical nursing practice in various pediatric nursing settings, as well as opportunities for nurses with limited experience, both in terms of human and physical environments, to learn about pediatric nursing. In 2012, we implemented an intervention program utilizing a pediatric nursing care model. Six weeks after the intervention, improvement was observed in the frequency of implementation for most items. However, it was not clear if there was a difference in the effects of the intervention between participants with experience in different settings [20]. Therefore, an intervention program designed for nurses with five or less years of pediatric nursing experience and aimed at enhancing ethical nursing practice, was implemented. The effects of the program have been published [8].

The current study aimed to elucidate the effects of the program on participants who had experience only of pediatric nursing, and those who had nursing experience in other specializations. This was achieved through the implementation of an intervention program designed for nurses with five or fewer years of pediatric nursing experience to enhance ethical nursing practice through the use of PNCM. This study's findings can be utilized in the education of registered nurses in pediatric wards in Japan who have had diverse experiences since their generalist nursing education.

\section{Term Definition}

Pediatric Nursing Care Model: The prototype Pediatric Nursing Care Model (PNCM) was developed in 1997. It concisely describes typical examples of ethical nursing practice for pediatric patients who undergo examinations and treatment, as well as their families. The prototype, containing over 40 items, was introduced to clinical nurses, and the recognition of ethical nursing practice among them was shown to have improved [21]. In 2012 we developed a simplified version of the PNCM checklist, containing 24 items; its validity and reliability have been verified (Cronbach's $\alpha=0.973$ ). The simplified checklist and forms, which were to be completed with practical examples, were used in an intervention program for nurses in order to reinforce their ethical practices [20].

\section{Methods}

\subsection{Subjects}

Invitations to participate were sent to hospitals, and a total of 32 nurses with five or fewer years of pediatric nursing experience were recruited before the first intervention. Multiple options for the time and date of the first intervention were proposed, and participants chose their preferred scheduling.

\subsection{Intervention Program and Data Collection}

Prior to the intervention, subjects were asked to confirm how often they apply 
the 24 PNCM items in practice by completing a simplified PNCM checklist, using a four-point Likert scale (4: always; 3: almost always; 2: rarely; 1: never). Thereafter, subjects attended a 30-minute mini-lecture, main content of the lecture is the necessity and the theoretical meaning of PNCM, and were requested to complete a form using examples from their practice. Next, subjects rated their likelihood of applying PNCM items by completing a simplified PNCM checklist, the same checklist used in the first step. Two months after the initial assessments and lecture, another PNCM checklist and practice example form were mailed to participants, who were asked to complete them and return them to the researcher.

Three months after the intervention, the results of the first and second months were mailed to the subjects, along with positive comments. At that time, subjects were also asked to complete a survey related to their nursing practice, changes in the reactions of pediatric patients and their families, and issues to be addressed going forward. The 30-minute mini-lecture and each PNCM checklist and practice example form were interventions and were also used as data for analysis.

\subsection{Analysis}

Quantitative data on the frequency of implementation and the likelihood of implementation were aggregated using Microsoft Excel software (Microsoft Corporation, Santa Rosa, CA). Median values were compared and a rank-sum test was performed, using SPSS Ver. 22 (IBM, Chicago, IL).

Qualitative, inductive analysis was performed using the descriptive details contained in respondents' practice examples, as well as the descriptive responses provided three months following the intervention. We sought advice from experts in pediatric nursing to ensure validity.

\subsection{Ethical Considerations}

Participation was voluntary. At the beginning of the intervention, the study purpose was explained to participants, and they provided informed consent to participate. Participants were assured of anonymity. This study was approved by the research ethics review committee of the Kobe City College of Nursing.

\section{Results}

\subsection{Participant Characteristics}

A total of 32 nurses participated in the intervention, of whom 22 provided valid responses (68.6\%). Among those who provided valid responses, 13 had experience only in pediatric nursing, and nine in other nursing areas. The mean number of years of experience among those who had experience only in pediatric nursing was 2.6 ( 1 - 5 years). The mean number of years of overall nursing experience among those who had experience in other nursing areas was 16.3 (5 - 30 years); the mean number of years of pediatric nursing experience among this 
group was 2.9 (1 - 4 years).

\subsection{Frequency of Practicing Checklist Items}

Changes in the frequency of practicing PNCM items between the initial survey and the survey conducted two months later are contained in Table 1. Among those with experience in other nursing areas, a significant difference was observed in frequency of practice for the following four items $(\mathrm{p}<0.05)$ : (2) One of the physicians, nurses, or parents provides children with explanations regarding the medical examinations/procedures or confirms them in advance; (13) When children cry, you implement other appropriate measures rather than forcing them to obey; (23) Following the completion of medical examinations/procedures, you provide children with follow-up instructions; and (24) You check the children's responses following implementation of the medical examinations/procedures.

Among those with experience only in pediatric nursing, improvements were observed in the following five items ( $\mathrm{p}<0.05)$ : (1) You greet children, introduce yourself, and inform them that you are the nurse in charge; (8) You explain medical examinations/procedures (including their purpose and methods) to children, using easy-to-understand expressions, even when their parents are present; (11) You provide children with explanations and talk to them during each stage of the examinations/procedures; (17) You avoid talking with other healthcare professionals about subjects not related to medical examinations/procedures; and (18) When examinations/procedures have not yet been completed, you avoid using expressions that may lead children and their parents to mistakenly think that they have been completed.

Among those with experience in other nursing areas, the median score for the frequency of practicing the item: (1) You greet children, introduce yourself, and inform them that you are the nurse in charge, improved from a score of 1 to 3 . A significant difference in scores for this item was observed between those who have experience only in pediatric nursing and those who have experience in other nursing areas.

The frequency of practicing the following items two months after the intervention was higher in those who have experience only in pediatric nursing than in those who have experience in other areas: (3) You ask children in advance when they want to be informed of the medical examinations/procedures; (10) You do the best you can to prevent children from being fearful; and (11) You provide children with explanations and talk to them during each stage of the examinations/procedures.

Both the likelihood and frequency of practicing the following items decreased in those who have experience only in pediatric nursing: (7) You also inform parents of the explanations and method content provided for their children; (21) You consider the parents' feelings, saying: "You must have been worried"; and (22) You encourage parents to praise their children for having been brave. 
Table 1. Significant difference of each score.

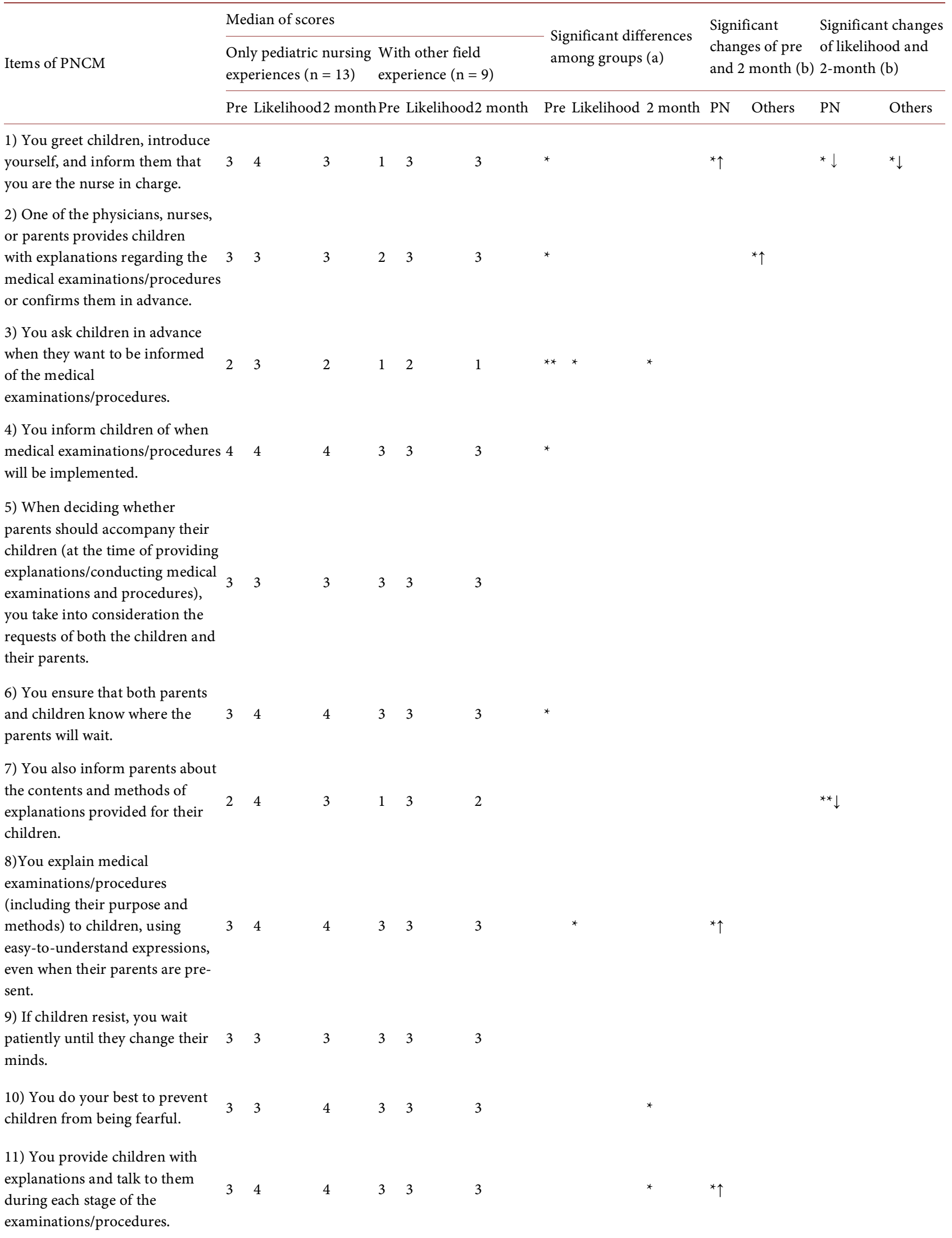




\section{Continued}

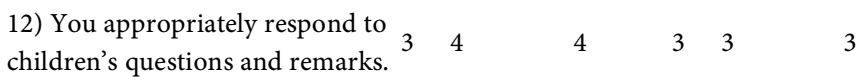

13) When children cry, you implement other appropriate measures rather than forcing $\begin{array}{llllll}2 & 2 & 2 & 2 & 2 & 2\end{array}$ them to obey.

14) You allow children to bring in their favorite things.

15) You distract children's attention away from medical examinations/procedures if

$\begin{array}{llllll}3 & 3 & 3 & 3 & 3 & 3\end{array}$

distress arises

16) When the

examinations/procedures take longer than expected, you give

$\begin{array}{llllll}3 & 4 & 3 & 3 & 3 & 3\end{array}$
parents an update on their progres

17) You avoid chatting with other healthcare professionals about subjects not related to medical

$\begin{array}{llllll}3 & 4 & 4 & 4 & 4 & 4\end{array}$
$* \uparrow$ examinations/procedures.

18) When examinations/ procedures have not yet been completed, you avoid using expressions that may lead children and their parents to mistakenly think that they have been completed.

19) You verbally inform children and their parents that examinations/procedures have been completed.

20) You praise children for having been brave.

21) You consider the parents

feelings, saying: "You must have $\begin{array}{llllll}3 & 4 & 3 & 3 & 4\end{array}$
been worried."

22) You encourage parents to praise their children for having been brave.

23) Following the completion

of medical examinations/ procedures, you provide children

with follow-up instructions.

24) You check the children's responses following implementation of the medical examinations/procedures.

※4-point Likert scale (4: always; 3: almost always; 2: rarely; 1: never), a: Mann-Whitney $\mathrm{U}$ test; b: Wilcoxon test, ${ }^{*}: \mathrm{p}<0.05,{ }^{* *}$ : $\mathrm{p}<0.01$. $\uparrow:$ increasing of the frequency, $\downarrow$ : decreasing of the frequency.

\subsection{Changes in Practice Examples}

Changes in participants' descriptions of examples of nursing practice are con- 
tained in Table 2. Compared to participants who have experience in other nursing areas, those who have experience only in pediatric nursing provided a larger volume of descriptions for the following categories of pediatric nursing practice, both in the initial survey and the two-month follow-up survey: "timing of the implementation"; "do greetings and self-introduction"; and "listen to the child's feelings and requests".

Table 2. Comparison of categories of nursing practice according to the description of practice cases at the first session and after two months.

\begin{tabular}{|c|c|c|c|c|}
\hline \multirow[b]{2}{*}{ Categories of nursing practice for children } & \multicolumn{2}{|c|}{ Only pediatric nursing experiences } & \multicolumn{2}{|c|}{ With other field experiences } \\
\hline & First session & After two months & First session & After two months \\
\hline Explain the procedure & 18 & 21 & 12 & 10 \\
\hline Talk to the child & 15 & 17 & 13 & 13 \\
\hline Timing of the implementation & 12 & 11 & 1 & 2 \\
\hline Do greetings and self-introduction & 6 & 8 & 2 & 6 \\
\hline Pay attention to the child to avoid a sense of fear & 3 & 4 & 1 & 4 \\
\hline Distract the child's attention & 2 & 1 & - & 4 \\
\hline Provide explanation again & 1 & 3 & - & 1 \\
\hline Bring the child's possessions & 1 & 1 & - & 1 \\
\hline Ask the child to choose how to perform a part of the procedure & - & 2 & 2 & 3 \\
\hline Convey that the child's mother is nearby & - & 3 & 3 & 1 \\
\hline Speak to the child at the end of the procedure & - & 8 & - & 4 \\
\hline $\begin{array}{l}\text { Confirm from the child or his/her parents whether the parents are } \\
\text { present }\end{array}$ & - & 4 & - & 3 \\
\hline Praise and encourage the child & - & 3 & - & 2 \\
\hline Convey the site and posture for the procedure & - & 3 & - & 1 \\
\hline Prepare to complete the procedure smoothly & - & 1 & - & 2 \\
\hline Respond to the child's questions & - & 1 & - & 2 \\
\hline Bring the child's favorite thing & - & 1 & - & 1 \\
\hline Did not confirm whether the child was informed of the procedure & - & 1 & - & - \\
\hline Confirm whether the child was informed of the procedure & - & 3 & - & - \\
\hline Listen to the child's feelings and requests & 7 & 5 & 1 & - \\
\hline Perform the procedure by holding the child by force & 7 & - & 2 & 2 \\
\hline Explain nothing to the child beforehand & 9 & - & 4 & - \\
\hline Conduct necessary preparations and environmental maintenance & 1 & - & 5 & - \\
\hline Say to the child "I'm sorry" & 1 & - & 1 & - \\
\hline $\begin{array}{l}\text { Convey that the child will be at risk if he/she does not obey the } \\
\text { instructions }\end{array}$ & 1 & - & 1 & - \\
\hline Confirm and explain the implementation of the procedure to the parents & & 3 & 7 & 2 \\
\hline
\end{tabular}


No descriptions for "distract the child's attention" were given in the initial survey by those who have experience in other nursing areas. However, in the survey conducted two months post-intervention, they gave more descriptions than those who have experience only in pediatric nursing.

In the two-month follow-up survey, no descriptions were provided for "explain nothing to the child beforehand" by any of the participant groups; those who have experience only in pediatric nursing provided no descriptions for "perform the procedure by holding the child by force," whereas those who have experience in other areas gave descriptions for this item in the way similar to the initial survey.

For "confirm and explain the implementation of the procedure to the parents," the frequency of practice decreased in both groups in the two-month follow-up survey.

\subsection{Changes in Patient Reactions}

Changes in descriptions related to the verbal behavior of pediatric patients and their parents are shown in Table 3. In both participant groups, the number of descriptions of children saying they "children agree [with the explanation of how-to proceed]" increased at the two-month follow-up. For "children remain silent," "children laugh and smile," and "children show no major response," the number of descriptions increased among those who have experience in other nursing areas at the two-month follow-up.

Table 3. Comparison of categories of children's and their parents' speech and behavior in the description of the practice cases at the first session and after two months.

\begin{tabular}{|c|c|c|c|c|}
\hline \multirow[b]{2}{*}{ Categories of children's speech and behavior } & \multicolumn{2}{|c|}{ Only pediatric nursing experiences } & \multicolumn{2}{|c|}{ With other field experiences } \\
\hline & First session & After two months & First session & After two months \\
\hline Children's' agree (with explanation of how-to-proceed) & 10 & 22 & 2 & 15 \\
\hline Children say I hate it & 13 & 15 & 1 & 2 \\
\hline Children cry and refuse it & 12 & 6 & 4 & 1 \\
\hline Children show rejection & 5 & 6 & 4 & 5 \\
\hline Children's autonomous actions & 3 & 8 & 5 & 5 \\
\hline Children remain silent & 5 & 2 & & 7 \\
\hline Children request waiting & 2 & 3 & & 1 \\
\hline Children laugh and smile & 7 & & 4 & 6 \\
\hline Children show no major response & 4 & & 5 & 5 \\
\hline Children show surprise at or questions for the procedure & & 10 & & 1 \\
\hline Children show satisfaction & & 7 & & 4 \\
\hline Children request something by themselves & & 4 & & 2 \\
\hline Children show anxious face & & 2 & & 1 \\
\hline The parents agree & 8 & 2 & 4 & 17 \\
\hline The parents praise the patient for his/her patience & 3 & 2 & 3 & 6 \\
\hline The parents persuade children & 9 & & 2 & \\
\hline The parents respond to their child's speech and behavior & 4 & & 2 & \\
\hline
\end{tabular}


In the initial survey, no descriptions were given by either of the participant groups for "children show surprise at or questions the procedure"; "children show satisfaction"; and "children request something by themselves." However, two months thereafter, a large number of descriptions for these items were provided by those who have experience only in pediatric nursing. For "the parents agree" and "the parents praise the patient for his/her patience," the two participant groups provided approximately the same number of descriptions in the initial survey, whereas two months thereafter, those who have experience in other areas provided more descriptions.

No descriptions for "the parents persuade children", "the parents respond to their child's speech and behavior" and "the parents apologize" were provided by either of the participant groups in the survey conducted two months after the initial survey.

\subsection{Descriptive Responses at Three-Month Follow-up}

Those who have experience in other nursing areas provided the following descriptions at the three-month follow-up: "started checking with parents about explanations given to children"; "started answering questions from children"; "started giving explanations concerning medical procedures progress"; "started using techniques to distract the child during the procedure"; "became able to consider parents' situation"; "children are no longer upset following medical procedures"; and "would like to start improving on aspects I can currently work on.”

Those who have experience only in pediatric nursing provided the following descriptions: "started recommending explanations for parents"; "started waiting for appropriate timing"; "started checking responses from patients and family following practice"; and "anxiety in pediatric patients and their family decreased." The description "collaboration with parents needs to be worked on" suggested that they considered it necessary to address issues related to nursing practice and involving patients' parents (Table 4).

\section{Discussion}

\subsection{Improvement among Non-Pediatric Nurses}

Among those who have experience in nursing areas other than pediatrics, the frequency of practicing the following items significantly increased from the start of the intervention to the two-month follow-up survey: respecting children's rights to know about medical procedures through the provision of explanations, and facilitating children's voluntary cooperation through means other than pinning them down, protecting their dignity in the process. These items are a basic part of the ethical practice of pediatric nursing. In order for a nurse to fulfill their responsibilities, they need to check the child's responses to performed procedures and general nursing practice. Nurses with limited pediatric nursing experience who are working in a pediatric-adult mixed ward, need to 
Table 4. Comparison of changes in recognition among participants by category, 3 months following intervention.

\begin{tabular}{ll}
\hline Nurses with experience in areas other than pediatric nursing & Nurses with experience only in pediatric nursing \\
\hline Children are no longer upset following medical procedures & Anxiety in pediatric patients and their family decreased \\
Started checking with parents about explanations given to children & Started recommending explanations for parents \\
Became able to consider parents' situations & Started waiting for appropriate timing \\
Started answering questions from children & Started checking response from patients and family following practice \\
Started giving explanations concerning medical procedures' progress & Collaboration with parents needs to be worked on \\
Started using techniques to distract the child during the procedure & I should acknowledge parents' effort \\
Would like to start improving on aspects which I can currently work on & I should tell patients and their families when I finish my shift
\end{tabular}

address specific issues that arise in this context, including hesitation in providing patient-centered care to pediatric patients and lack of pediatric nursing education; providers of nursing education should focus on communicating the uniqueness of pediatric nursing, while respecting the career of nurses who have limited experience in pediatric nursing [22]. Factors for improving the pediatric nursing skills of nurses working in a mixed pediatric-adult ward were identified by Watanabe et al. (2013) as observing and copying pediatric nursing practice and implementing it, accumulating pediatric nursing techniques, and studying basic pediatric nursing again. Our program provided nurses with a meaningful opportunity to learn the basics of pediatric nursing. It is necessary to continue providing education opportunities to nurses who have experience in nursing areas other than pediatric nursing [23].

\subsection{Necessity of Greetings and Self-Introductions}

Scores for the likelihood of implementing the PNCM item, (1) You greet children, introduce yourself, and inform them that you are the nurse in charge, were high among those who have experience in nursing areas other than pediatric nursing. However, the frequency of practicing this item was higher in those who have experience only in pediatric nursing. In the study by Nakajima et al. (2002) on nurses' treatment of patients, it was reported that $20 \%$ or more participants indicated that nurses do not introduce themselves to their patients [24]. Similarly, Takahashi et al. (2009) studied inpatients and reported that participants indicated a low level of satisfaction with self-introduction by nurses who were responsible for patients, either on a continuous or daily basis [25]. It can be assumed, then, that not all nurses regularly greet and introduce themselves to patients, even in pediatric nursing. Participants in this study, including those who have experience in nursing areas other than pediatric nursing, may need to address this shortcoming. Additionally, Ito et al. (2005) pointed out that the evaluation of greetings and self-introduction, which is one item of the OSCE (Objective Structured Clinical Examination) for interviews in the area of healthcare, varies between evaluators who observe the same scene, and there tends to be disagreement on the evaluation of assessed healthcare professionals [26]. The type of greeting and self-introduction required in such situations goes beyond 
merely telling patients their name, but should also include a clarification of the nurse's identity and responsibilities, and should serve to alleviate tension between nurses, pediatric patients and their families. Nurses need to tell patients and their families that greetings and self-introduction have ethical significance, namely laying the foundation of a relationship between health professionals and patients. Greetings and self-introduction should be performed based on a shared understanding of the above.

\subsection{Differences in Improvement of Nursing Practice}

Among nurses who had experience only in pediatric nursing, improvement was observed in their practice, including details important in building a relationship of trust between the patient and the health professional, information disclosure and supportive care.

The frequency of practicing all of the following items was higher in those who have experience only in pediatric nursing: (3) You ask children in advance when they want to be informed of the medical examinations/procedures; (10) You do the best you can to prevent children from being fearful; and (11) You provide children with explanations and talk to them during each stage of the examinations/procedures.

The mean number of years of nursing experience among nurses who had experience in other areas was 16.3 whereas that among those with experience only in pediatric nursing was 2.8. Kasai et al. (2010) implemented an education program on diabetes for 26 nurses in a ward, lasting 10 months and consisting of monthly group lectures (including an evaluation of the degree of understanding) as well as individual seminars with small groups of two to three nurses who had a similar number of years of experience [27]. Following the program, compared to nurses with five or more years of experience, the correct answer rates of tests on the knowledge of diabetes increased to a greater extent in those with one to five years' experience. Sakai (2015) implemented a program for nursing ethics, where goals were set by skill, in line with the clinical ladder, including skills required for the first year of clinical experience. Goals were also set by role, such as leader. A comparative analysis of evaluations three months following the program found that higher evaluations were given to those in their first year of clinical practice than to those with six to seven years' experience [28].

Funashima (2015) has pointed out that it is difficult to plan and provide education programs for experienced nurses as their interest and areas of specialization become highly individualized as their experience increases, while it is easier to do so for nurses with fewer years of experience. Funashima's findings may apply to the current study, in which a difference was observed in the degree of improvement in pediatric nursing practice between nurses with six or more years of experience and those with less than six years' experience, who have experience only in pediatric nursing. Those with six or more years of experience have experienced various clinical settings, and their individualized customary 
practice and values may have contributed to such a difference [29]. Therefore, when implementing a pediatric nursing education program, it is necessary to anticipate that the effects of the program may vary due to differences in characteristics between nurses with experience in areas other than pediatric nursing and those with experience only in pediatric nursing.

\subsection{Raising Awareness of Issues Involving Patients' Parents}

Among nurses who have experience only in pediatric nursing, scores for the likelihood of practicing the following items decreased in the survey conducted two months following the intervention: (7) You also inform parents about the contents and methods of explanations provided for their children; (21) You consider the parents' feelings, saying, "You must have been worried"; and (22) You encourage parents to praise their children for having been brave. These items are related to practice involving patients' parents. For "The parents agree" and "The parents praise the patient for his/her patience," the two participant groups provided approximately the same number of descriptions in the initial survey, whereas two months thereafter, those who have experience in areas other than pediatric nursing provided more descriptions compared to those with experience only in pediatric nursing.

Tsuchiya et al. (2004) examined issues in communication faced by nurses working in a pediatric-adult mixed ward and those working in a pediatric ward. The researchers found that those working in a pediatric ward experienced a higher degree of difficulty in communicating with patients' families, and it could be assumed that this is a challenge among nurses who have experienced only pediatric nursing. Descriptive responses provided in the survey conducted three months after the intervention included comments indicating participants' awareness of issues related to nursing practice involving patients' parents, as well as their intention of improving such issues. The responses included phrases such as, "collaboration with parents is an issue" and "I should acknowledge parents" effort." Findings from the implementation of this program suggest that it is necessary to add to it components designed to improve communication between patients' families and nurses who have experience only in pediatric nursing [30].

Our findings suggest that the intervention program may to an improvement in certain characteristics of ethical nursing practice. It is possible to apply our program results to nurses working not only in pediatric nursing, but also in a wide range of other settings, including pediatric-adult mixed wards and clinics. However, it is necessary to understand nurses' educational background, taking into account differences in the degree of experience.

\section{Study Limitations}

The current study involved a small sample-13 nurses with experience only in pediatric nursing and nine with experience in areas other than pediatric nursing. Future iterations of the program therefore need to increase the number of par- 
ticipants. Since the educational background of participants was not examined prior to this study, it is necessary to analyze the effects of nursing education when taking into account participants' education background.

\section{Conclusion}

This study implemented an intervention program designed for nurses with five or less years of pediatric nursing experience to enhance ethical nursing practice through the use of PNCM. It elucidated differences in the effects of the program between participants with experience in different settings. Among those with experience in nursing areas other than pediatrics, items related to basic ethical practices in pediatric nursing significantly increased in frequency from before the intervention to two months after. Among nurses who only had experience in pediatric nursing, improvement was observed in their practice as well. This included building trust relationships between patients and professionals, providing information and supportive care, and increasing awareness of practice-related issues regarding patients' parents. The findings suggest that the intervention program could help nurses improve certain aspects of ethical nursing practice. Moreover, the results could be applied to nurses working not only in pediatric nursing but also a wide range of other settings, such as mixed pediatric-adult wards and clinics.

\section{Acknowledgements}

This study forms part of a doctoral dissertation at the Graduate School of Nursing, the Kobe City College of Nursing. I would like to express my sincere gratitude to study participants and Professor Keiko Ninomiya for their contributions. This study was funded by a research grant from the Japan Society for the Promotion of Science (2013-17).

We would like to thank Editage (http://www.editage.com/) for English language editing.

\section{Conflicts of Interest}

The authors declare no conflicts of interest regarding the publication of this paper.

\section{References}

[1] Ministry of Health, Labour and Welfare (2017) Survey of Health Institutions in Japan. https://www.mhlw.go.jp/toukei/saikin/hw/iryosd/17/dl/02sisetu29-1.pdf

[2] Funashima, N., Katada, N., Oikawa, I., Tsutsui, M., Hirabayashi, Y., Murata, K. and Hirosue, Y. (1992) States Analysis about Attending and Visiting for Hospitalized Children in Pediatric Wards. Proceedings of The Japan Society of Nursing, 23, 134-137. (In Japanese)

[3] Kobayashi, K. and Hohashi, N. (2013) A Nationwide Survey on the Current Status of Family Accompaniment: Visits to Hospitalized Children and Difficulties and Challenges Encountered by Nurses in Family Care. Journal of Japanese Society of 
Child Health Nursing, 22, 129-134. (In Japanese)

[4] Inoue, R. and Kodama, C. (2004) Environmental Conditions for Children and Their Parents in Pediatrics Wards; According to Questionnaires from the Nurses Working in Kanagawa Hospitals. The Journal of Child Health, 63, 295-301. (In Japanese)

[5] Kusayanagi, H. (2004) Difficulty for the Nurses Who Take Care of Children and Adults in the Same Ward. Journal of Japan Academy of Nursing Science, 24, 62-70. https://doi.org/10.5630/jans1981.24.2_62

[6] Kobayashi, Y., Hoshi, N., Shimoda, T. and Sugiyama T. (2008) Awareness and Actions of Nurses Who Come into Contact with Hospitalized Children: Focusing on What Is in the Children's Best Interest. Journal of Health Care and Nursing, 4, 10-19. (In Japanese)

[7] Ishiura, M., Machida, W. and Sakamoto, M. (2012) Nursing Ethics in Mixed Wards. Pediatric Nursing, 35, 986-993. (In Japanese)

[8] Matsumori, N. (2018) Effects of an Intervention Program for Promoting Ethical Practices among Pediatric Nurses. Comprehensive Child and Adolescent Nursing, 42, 203-221. https://doi.org/10.1080/24694193.2018.1470704

[9] Ministry of Health (1959) The Welfare of Children in Hospital, Platt Report. Her Majesty's Stationery Office, London.

[10] Atherton, T. (1993) Childcare Nursing: The Faltering First Steps. Nursing Standard, 7, 50-51. https://doi.org/10.7748/ns.7.21.50.s63

[11] Benner, P. (1984) From Novice to Expert: Excellence and Power in Clinical Nursing Practice. Addison-Wesley, Menlo Park, CA. https://doi.org/10.1097/00000446-198412000-00025

[12] Price, S. (1993) Children's Nursing: Lessons from the Past. Nursing Standard, 7, 31-35. https://doi.org/10.7748/ns.7.50.31.s42

[13] Kalbfuss, N.P. and Deanus, L.J. (2017) Reflection on the Dual-Field Adult and Child Nursing Degree Course. Nursing Standard, 31, 48-51.

https://doi.org/10.7748/ns.2017.e10319

[14] Doyle, C., Murphy, M., Begley, T. and King, C.B. (2008) Education of Children's Nurses in Ireland: An Update. Pediatric Nursing, 20, 41-45.

https://doi.org/10.7748/paed.20.8.41.s29

[15] Festini, F. (2013) Pediatric Nursing in Italy: Struggling to Survive. Issues in Comprehensive Pediatric Nursing, 36, 88-97. https://doi.org/10.3109/01460862.2013.779766

[16] Conway, R. (1996) The Mysteries of the Milton Tank! Transition from Adult to Pediatric Nursing, for the Experienced Nurse. Nursing Praxis in New Zealand, 11, 27-31.

[17] Hollywood, E. (2011) The Lived Experiences of Newly Qualified Children's Nurses. British Journal of Nursing, 20, 661-671. https://doi.org/10.12968/bjon.2011.20.11.665

[18] Love, B. (2005) Baccalaureate-Linked Oncology Nursing Education: McMaster University's Paediatric and Adult Oncology Nursing Program. Canadian Oncology Nursing Journall Revue canadienne de soins infirmiers en oncologie, 15, 80-86. https://doi.org/10.5737/1181912x1528086

[19] Runton, N.G. and Toth, J.C. (1998) Introducing the Basic Knowledge Assessment Tool for Pediatric Critical Care Nursing. Critical Care Nurse, 18, 67-72. https://doi.org/10.4037/ccn1998.18.3.67

[20] Matsumori, N. (2016) Nurse's Impressions and Changes after the Workshops Using 
the Pediatric Nursing Care Model. Journal of Nursing Education and Practice, 6, 82. https://doi.org/10.5430/jnep.v6n9p82

[21] Matsumori, N., Ninomiya, K., Ebina, M., Katada, N., Katsuda, H., Kosako, Y., Sasaki, S. and Fukuchi, M. (2006)Practical Application and Evaluation of a Care Model for Informing and Reassuring Children Undergoing Medical Examinations and/or Procedures (Part 2), Methods of Relating and Practical Nursing Techniques that Best Bring out the Potential of Children. Japan Journal of Nursing Science, 3, 51-64. https://doi.org/10.1111/j.1742-7924.2006.00052.x

[22] Kurata, S., Nagata, M. and Aoki, Y. (2016) Issues and Measures of Education for Novices of Pediatric Nursing in the Mixed Ward as the Educators. Journal of the Japanese Society of Human Caring Research, 7, 11-18. (In Japanese)

[23] Watanabe, K., Horikoshi, Y., Kagawa, Y., Kumagai, N., Azuma, H. and Takahashi, E. (2013) Factors of Improvement for Nursing Skill in Pediatric Nursing on Mixed Wards. Proceedings of The Japan Society of Nursing, 43, 141-144. (In Japanese)

[24] Nakashima, T., Yamamoto, C., Tatsuta, S. and Nishioka M. (2002) Inpatients' Opinions about the Nursing Service: A Report from Questionnaire Findings. Kochi Journal of Medicine, 29, 31-37.

[25] Takahashi, M., Hirasawa, S. and Yamaguchi, A. (2008) Results of Satisfaction Survey for Inpatients in 2008. Medical Journal of Morioka Red Cross Hospital, 18, 40-49. (In Japanese)

[26] Ito, T., Aoki, S., Oomine, H., Kawai, Y., Kasai, K., Kanazawa, E. and Ootake, S. (2005) OSCE Evaluation Discrepancies in Medical Interview Settings-Based on an Analysis of Human Errors. Journal of Japanese Dental Education Association, 21, 21-30.

[27] Kasai, Y., Akimoto, Y., Nakayama, C., Narumi, M. and Chiba M. (2010) Effect of Nursing Education Program in Nursing for Diabetes Mellitus. The Medical Journal of Kuroishi City Hospital, 16, 32-37.

[28] Sakai, K. (2015) Effect of Education Program for Nursing Ethics in Juntendo Hospital. Nursing Business, 48-63. (In Japanese)

[29] Funashima, N. (2015) Basic Knowledge for Plan/Do/See of Education Program in a Hospital. 2nd Edition, IGAKU-SHOIN Ltd, Tokyo.

[30] Tsuchiya, Y., Ishii, K. and Suzuki, C. (2004) Nurses' Recognition on Their Communication with Their Inpatient Children and Families. Bulletin of Fukushima Medical University School of Nursing, 6, 73-80. (In Japanese) 